\title{
Impact of adjuvant hormonotherapy on radiation-induced breast fibrosis according to the individual radiosensitivity: results of a multicenter prospective French trial
}

Céline Bourgier ${ }^{1}$, Florence Castan ${ }^{1}$, Olivier Riou ${ }^{1}$, Tan-Dat Nguyen ${ }^{2}$, Karine Peignaux ${ }^{3}$, Claire Lemanski ${ }^{1}$, Jean-Léon Lagrange ${ }^{4}$, Youlia Kirova ${ }^{5}$, Eric Lartigau ${ }^{6}$, Yazid Belkacemi ${ }^{4}$, Sofia Rivera7, Georges Noël ${ }^{8}$, Sébastien Clippe ${ }^{9}$, Françoise Mornex $^{10}$, Christophe Hennequin ${ }^{11}$, Sophie Gourgou ${ }^{1}$, Muriel Brengues ${ }^{1}$, Pascal Fenoglietto $^{1}$, Esat Mahmut Ozsahin ${ }^{12}$ and David Azria ${ }^{1}$

\footnotetext{
${ }^{1}$ Institute de Recherche en Cancérologie de Montpellier, Inserm U1194, Université de Montpellier, Institut Régional du Cancer de Montpellier, Montpellier, France

${ }^{2}$ Institute Jean Godinot, Reims, France

${ }^{3}$ Centre GF Leclerc, Dijon, France

${ }^{4}$ AP-HP Henri Mondor, Créteil, France

${ }^{5}$ Institute Curie, Paris, France

${ }^{6}$ Centre Oscar Lambret, Lille, France

${ }^{7}$ Gustave Roussy, Villejuif, France

${ }^{8}$ Centre Paul Strauss, Strasbourg, France

${ }^{9}$ Centre Marie Curie, Valence, France

${ }^{10}$ Centre Hospitalier Lyon Sud, Pierre Bénite, France

${ }^{11}$ AP-HP Saint-Louis, Paris, France

${ }^{12}$ Centre Hospitalier Universitaire Vaudois, Lausanne, Switzerland

Correspondence to: David Azria, email: david.azria@icm.unicancer.fr

Keywords: radiotherapy; breast cancer; hormonotherapy; individual radiosensitivity; late effects

Received: November 30, 2017 Accepted: February 25, 2018 Epub: March 02, 2018 Published: March 20, 2018

Copyright: Bourgier et al. This is an open-access article distributed under the terms of the Creative Commons Attribution License 3.0 (CC BY 3.0), which permits unrestricted use, distribution, and reproduction in any medium, provided the original author and source are credited.
}

\section{ABSTRACT}

Background: To evaluate risk of severe breast fibrosis occurrence in patients treated by breast-conserving surgery, adjuvant radiotherapy and hormonotherapy (HT) according to individual radiosensitivity (RILA assay).

Results: HT- and RILA ${ }^{\text {high }}$ were the two independent factors associated with improved breast-fibrosis free survival (BFFS). BFFS rate at $\mathbf{3 6}$ months was lower in patients with RILA ${ }^{\text {low }}$ and $\mathrm{HT}^{+}$than in patients with RILA ${ }^{\text {high }}$ and $\mathrm{HT}^{-}(\mathbf{7 5 . 8} \%$ and $100 \%$, respectively; $p=0.004$, hazard ratio 5.84 [95\% confidence interval (CI) 1.8-19.1]). Conversely, BFFS at 36 months was comparable in patients with RILA ${ }^{\text {high }}$ and $\mathrm{HT}^{+}$and in patients with RILA ${ }^{\text {low }}$ and HT- $^{-}(89.8 \%$ and $93.5 \%$, respectively; $p=0.39$, hazard ratio 1.7 [95\% CI 0.51-5.65]), showing that these two parameters influenced independently the occurrence of severe breast fibrosis. BFFS rate was not affected by the HT type (tamoxifen or aromatase inhibitor) and timing (concomitant or sequential with radiotherapy).

Conclusions: HT and RILA score independently influenced BFFS rate at $\mathbf{3 6}$ months. Patients with RILA ${ }^{\text {high }}$ and HT' $^{-}$presented an excellent BFFS at 36 months (100\%).

Materials and methods: Breast Fibrosis-Free Survival (BFFS) rate was assessed relative to RILA categories and to adjuvant $\mathrm{HT}^{\text {use }}\left(\mathrm{HT}^{+}\right.$and $\mathrm{HT}^{-}$, respectively) in 


\section{a prospective multicentre study (NCT00893035) which enrolled 502 breast cancer patients (456 evaluable patients). Breast fibrosis was recorded according to CTCAE v3.0 grading scale; RILA score was defined according to two categories ( $<12 \%$ : RILA $^{\text {low; }} \geq \mathbf{1 2} \%$ : RILA ${ }^{\text {high }}$ ).}

\section{INTRODUCTION}

The efficacy of adjuvant breast cancer radiotherapy after breast-conserving surgery is now well established. The Early Breast Cancer Trialists' Collaborative Group (EBCTCG) meta-analysis showed that the addition of radiotherapy significantly reduces breast cancer recurrence and death [1]. In addition to radiotherapy, endocrine treatment (tamoxifen, TAM, and/or aromatase inhibitors, AI) also significantly decreases all recurrences and the 10year mortality rate for breast cancer [2].

However, late side effects have been reported in long-term survivor patients with better breast cancer outcome. These toxicities, such as radio-induced cardiotoxicity or poor cosmetic outcome, could impair the quality of life and affect the clinical benefit over time $[3,4]$. The risk factors of normal tissue radiosensitivity are related to the personal medical history and/or directly to the treatment [5]. It has been hypothesized that severe fibrosis occurs mostly in patients with micro-vascularization diseases (e.g., diabetes mellitus, hypertension, etc.) or with diseases related to excess collagen deposition (e.g., scleroderma). Other risk factors are related to the radiotherapy modalities (high total dose, high dose per fraction, large irradiated volume) and to the treatment combinations (e.g., endocrine therapy, chemotherapy, history of surgery) (reviewed in [6]).

Ionizing radiation blocks cells in the $\mathrm{G} 0 / \mathrm{G} 1$ and $\mathrm{G} 2 / \mathrm{M}$ phases of the cell cycle, and this effect is inhibited by estradiol $[7,8]$. Incubation of breast cancer cells with TAM or AIs, such as letrozole, promotes their accumulation in the $\mathrm{G} 0 / \mathrm{G} 1$ phase $[9,10]$. Moreover, TAM and radiotherapy increase the secretion of pro-fibrotic cytokines and transforming growth factor-beta (TGF- $\beta$ ), a key mediator of fibrogenesis $[11,12]$. On the basis of these preclinical observations, a clinical study assessed TAM pro-fibrotic properties in patients with breast cancer and showed that TAM increases the risk of lung fibrosis when given concomitantly with radiotherapy [13]. Similarly, an increased risk of lung fibrosis was also observed in animal models treated concomitantly with TAM and ionizing radiation [14]. However, other preclinical results suggest that TAM could have anti-fibrotic effects by inhibiting TGF$\beta 1$-mediated activation of fibroblasts through modulation of SMAD [15] and non-SMAD signaling pathways [16].

Patients- and treatments-related risk factors give a general trend of the probability to develop late radio-induced toxicities. A rapid and non-invasive predictive assay to identify hyper-reactive patients (i.e., patients at high risk of developing late radio-induced toxicity) is now available. This test is based on the evaluation by flow cytometry of radiation-induced CD8+ T-lymphocyte apoptosis (RILA). We previously demonstrated that patients with low RILA scores have a higher risk of severe breast fibrosis [17]. Moreover, in a longitudinal data repository study, we showed that RILA and treatment with TAM are two independent predictive factors of subcutaneous fibrosis in patients with breast cancer [18]. Specifically, in patients with low RILA scores or treated with TAM, the complication (grade 2 or more fibrosis)-free survival rate at 2 years was lower than in patients who did not receive TAM or with high RILA scores.

Therefore, here, we used data we collected during a prospective, multicenter French trial [17] to assess the risk of severe breast fibrosis occurrence in patients with breast cancer who underwent breast-conserving surgery, in function of the adjuvant hormonotherapy (TAM or AI) and individual radiosensitivity, monitored by RILA.

\section{RESULTS}

\section{Patients' characteristics}

As reported in 2015 [17], 456 patients with breast cancer received radiotherapy and had an evaluable blood sample. All patients underwent breast-conserving surgery followed by whole-breast radiotherapy $(n=456)$, tumor bed boost irradiation $(n=449)$, and lymph node radiotherapy $(n=108)$. Moreover, 143 patients $(31.4 \%)$ received adjuvant chemotherapy, and $349(76.5 \%)$ were treated with HT (TAM: $n=135$; AI: $n=214$ ) (Table 1).

The incidence of grade $\geq 2$ fibrosis was significantly higher in $\mathrm{HT}^{+}$than in $\mathrm{HT}^{-}$patients $(15.6 \%$ and $15.9 \%$ for TAM and AI, respectively, versus $5.6 \%$ for $\mathrm{HT}^{-}$patients; $p=0.018$ ) (Table 1). RILA score, tobacco smoking and breast volume were not significantly different in the HT subgroups ( $\mathrm{HT}^{-}$, TAM or $\left.\mathrm{AI}\right)$. No difference was also observed concerning the surgery type/margins and adjuvant systemic therapies (chemotherapy \pm trastuzumab). As nodal involvement was significantly higher in the $\mathrm{HT}^{+}$than in $\mathrm{HT}^{-}$group $(p=0.01)$, more patients in the TAM and AI subgroups underwent lymph node irradiation than in the HT $^{-}$group $(p=0.03)$. The tumor bed boost irradiation techniques were significantly different in the $\mathrm{HT}^{+}$and $\mathrm{HT}^{-}$ subgroups: electron beams were more frequently used in the TAM than in the AI group $(p=0.03)$ (Table 1$)$.

\section{Risk of breast fibrosis according to RILA and HT}

This prospective and multicenter French trial reported a 3-year BFFS rate of $87.8 \%$ [95\% CI 84.4-90.5] [17]. Adjuvant HT and RILA were the two independent factors for breast fibrosis relapse-free survival when 
Table 1: Characteristics and treatments of patients divided according to the use or not of hormonotherapy (tamoxifen, aromatase inhibitors, or none)

\begin{tabular}{|c|c|c|c|c|}
\hline & $\begin{array}{c}\text { No } \\
\text { hormonotherapy }\end{array}$ & Tamoxifen & $\begin{array}{l}\text { Aromatase } \\
\text { inhibitors }\end{array}$ & \\
\hline & $N=107(\%)$ & $N=135(\%)$ & $N=214(\%)$ & $P$-value* \\
\hline Median age (years, range) & $56(29-77)$ & $49(32-77)$ & $62(42-88)$ & $<0.001$ \\
\hline \multicolumn{5}{|l|}{ Fibrosis } \\
\hline No & $101(94.4)$ & $114(84.4)$ & $180(84.1)$ & 0.02 \\
\hline Yes & $6(5.6)$ & $21(15.6)$ & $34(15.9)$ & \\
\hline \multicolumn{5}{|l|}{ RILA } \\
\hline$<12 \%$ & $47(43.9)$ & $49(36.3)$ & $73(34.1)$ & 0.13 \\
\hline $12-20 \%$ & $35(32.7)$ & $44(32.6)$ & $61(28.5)$ & \\
\hline$\geq 20 \%$ & $25(23.4)$ & $42(31.1)$ & $80(37.4)$ & \\
\hline \multicolumn{5}{|l|}{ Tobacco smoking } \\
\hline Non smoker & $76(71.0)$ & $77(57.0)$ & $136(63.5)$ & 0.15 \\
\hline Active/former smoker & $29(27.1)$ & $52(38.5)$ & $66(30.8)$ & \\
\hline NA & $2(1.9)$ & $6(4.4)$ & $12(5.6)$ & \\
\hline \multicolumn{5}{|l|}{ Menopausal status } \\
\hline Premenopausal & $33(30.8)$ & $92(68.1)$ & $14(6.5)$ & $<0.001$ \\
\hline Postmenopausal & $71(66.4)$ & $41(30.4)$ & $200(93.5)$ & \\
\hline NA & $3(2.8)$ & $2(1.5)$ & 0 & \\
\hline \multicolumn{5}{|l|}{ Breast volume } \\
\hline Small & $40(37.4)$ & $45(33.3)$ & $50(23.4)$ & 0.06 \\
\hline Large & $53(49.5)$ & $68(50.4)$ & $120(56.1)$ & \\
\hline NA & $14(13.1)$ & $22(16.3)$ & $44(20.5)$ & \\
\hline \multicolumn{5}{|l|}{ T stage } \\
\hline 0 & 0 & $1(0.7)$ & $4(1.9)$ & 0.09 \\
\hline 1 & $96(89.7)$ & $112(83.0)$ & $182(85.1)$ & \\
\hline 2 & $9(8.4)$ & $22(16.3)$ & $28(13.1)$ & \\
\hline NA & $2(1.9)$ & 0 & 0 & \\
\hline \multicolumn{5}{|l|}{$\mathrm{N}$ stage } \\
\hline 0 & $100(93.5)$ & $109(80.7)$ & $180(84.1)$ & 0.01 \\
\hline 1 & $6(5.6)$ & $25(18.5)$ & $28(13.1)$ & \\
\hline 2 & 0 & $1(0.7)$ & $5(2.3)$ & \\
\hline 3 & 0 & 0 & $1(0.5)$ & \\
\hline NA & $1(0.9)$ & 0 & 0 & \\
\hline \multicolumn{5}{|l|}{ Type of initial surgery } \\
\hline Tumorectomy & $93(86.9)$ & $108(80.0)$ & $180(84.1)$ & 0.35 \\
\hline Quadrantectomy & $14(13.1)$ & $27(20.0)$ & $34(15.9)$ & \\
\hline \multicolumn{5}{|l|}{ Margins } \\
\hline Negative & $105(98.1)$ & $129(95.6)$ & $207(96.7)$ & 0.37 \\
\hline Positive & $1(0.9)$ & $6(4.4)$ & $6(2.8)$ & \\
\hline NA & $1(0.9)$ & 0 & $1(0.5)$ & \\
\hline \multicolumn{5}{|l|}{ Surgical area } \\
\hline$<50 \mathrm{~cm}^{3}$ & $57(53.3)$ & $72(53.3)$ & $104(48.6)$ & 0.68 \\
\hline
\end{tabular}




$\begin{array}{cccc}\geq 50 \mathrm{~cm}^{3} & 49(45.8) & 60(44.4) & 108(50.5) \\ \mathrm{NA} & 1(0.9) & 3(2.2) & 2(0.9)\end{array}$

Adjuvant

chemotherapy

$\begin{array}{lllcc}\text { No } & 71(66.4) & 86(63.7) & 156(72.9) & 0.16 \\ \text { Yes } & 36(33.6) & 49(36.3) & 58(27.1) & \end{array}$

Adjuvant trastuzumab

$\begin{array}{lcccc}\text { No } & 100(93.5) & 130(96.3) & 209(97.7) & 0.17 \\ \text { Yes } & 7(6.5) & 5(3.7) & 5(2.3) & \end{array}$

Node irradiation

$$
\begin{aligned}
& \text { Mammary gland only } \\
& \text { Supraclavicular } \pm \text { internal } \\
& \text { mammary chain }
\end{aligned}
$$

$17(15.9)$

Boost technique
$104(97.2)$

Yes

$\begin{array}{lc}\text { No } & 3(2.8) \\ \text { Yes } & 104(97.2) \\ & \\ \text { Photon } & 78(72.9) \\ \text { lectron } & 13(12.2) \\ \text { hytherapy } & 0 \\ \text { + electron } & 13(12.1) \\ \text { NA } & 3(2.8)\end{array}$

In RILA ${ }^{\text {high }}$ patients, adjuvant HT slightly increased the risk of severe breast fibrosis (HR $=2.43$ for TAM $[95 \%$ CI $0.67-8.88, p=0.177]$ and $\mathrm{HR}=2.12$ for $\mathrm{AI}[95 \%$ CI $0.61-7.40, p=0.236]$, without significant differences (Figure 2). The 36-month BFFS was 89.5\% (TAM) and $90 \%$ (AI) for $\mathrm{HT}^{+}$patients compared with the reference category (RILA ${ }^{\text {high }} / \mathrm{HT}^{-}$).

\section{Risk of breast fibrosis according to HT timing (co-HT or sq-HT)}

Compared with the reference category (RILA ${ }^{\text {high }} / \mathrm{HT}^{-}$), in RILA ${ }^{\text {low }}$ patients, the 36 -month BFFS rate was $73.9 \%$ in the co-HT and $76.9 \%$ in the sq-HT group without significant differences between groups (Figure 3). Both co-HT and sqHT increased the risk of severe fibrosis $(\mathrm{HR}=4.47[95 \% \mathrm{CI}$ 1.32-15.12], $p=0.016$ and $\mathrm{HR}=4.58$ [95\% CI 1.29-16.25], $p=0.018$, for the co-HT and sq-HT group, respectively).

Similar results were obtained for RILA ${ }^{\text {high }} / \mathrm{HT}^{+}$patients (Figure 3). The 36-month BFFS rates were $89.9 \%$ and $89.7 \%$ in the co-HT and sq-HT group, respectively. However, HT timing did not increase the risk of severe fibrosis $(\mathrm{HR}=2.05$ [95\% CI 0.54-7.76], $p=0.288$ and $\mathrm{HR}=2.35$ [95\% CI $0.69-8.07], p=0.174$, for co-HT and sq-HT, respectively). 


\section{DISCUSSION}

In the present study, data on late toxicities from a prospective and multicenter French study on patients with breast cancer were used to assess the interactions between HT and radiotherapy in breast fibrosis occurrence. Our results showed that patients with low RILA score and treated with HT had the highest risk of severe late side effects.

A large and exhaustive literature review was recently published and reported no difference in esthetic outcome and toxicities in patients with breast cancer who underwent sequential or concomitant endocrine treatments [19]. TAM use and timing, relative to radiotherapy, were studied in three retrospective studies with a very long follow-up ( $>8$ years) [20-22]. Pierce and colleagues reported a subgroup analysis of the Intergroup 0102 phase III randomized trial. Only grade 3 or more late toxicities were reviewed and no difference of lung toxicity was observed in patients who received concurrent and sequential TAM use [22]. The monocentric and retrospective study by Harris and colleagues also did not observe any difference in terms of late side effects (breast edema, arm edema, rib fractures, pneumonitis, 3- and 5-year cosmesis) between concurrent and sequential TAM use [21]. Similar findings were reported for concurrent and sequential AI use in two retrospective cohorts $[23,24]$ and in a randomized phase II clinical trial (Concomitant HOrmono-RadioTherapy, CO-
HO-RT, NCT00208273) that investigated the timing of endocrine therapy and radiotherapy in patients with breast cancer [25]. The long-term follow-up of the CO-HO-RT trial did not report any statistical difference regarding HT timing, but its translational sub-studies showed that low RILA values (used as a stratification factor) were associated with a higher risk of breast fibrosis [26]. Our present results confirm that HT timing does not affect the risk of breast fibrosis. In line with the CO-HO-RT results, we also observed that low RILA values were associated with higher risk of breast fibrosis, regardless of HT timing. More precisely, the association of low RILA score and HT significantly increased the risk of breast fibrosis by 5 - to 6 -fold. These results confirm our previous finding that TAM enhances breast fibrosis risk only in hypersensitive patients (i.e., patients with low RILA scores) [18].

While no data has been published on the molecular mechanisms involved in AI-related fibrosis, conflicting results have been reported about TAM role in fibrosis occurrence. Recent in vitro results showed that TAM prevents fibroblast activation by TGF- $\beta$ as effectively as a TGF- $\beta$ receptor kinase inhibitor (GW6604) [16]. Similarly, in another in vivo model (renal tubulointerstitial fibrosis), TAM could reduce renal fibrosis by decreasing the expression of extracellular matrix proteins and tissue TGF- $\beta$ [15]. On the other hand, Bese and Yavas [14, 27] observed that the concomitant use of TAM, but not AI

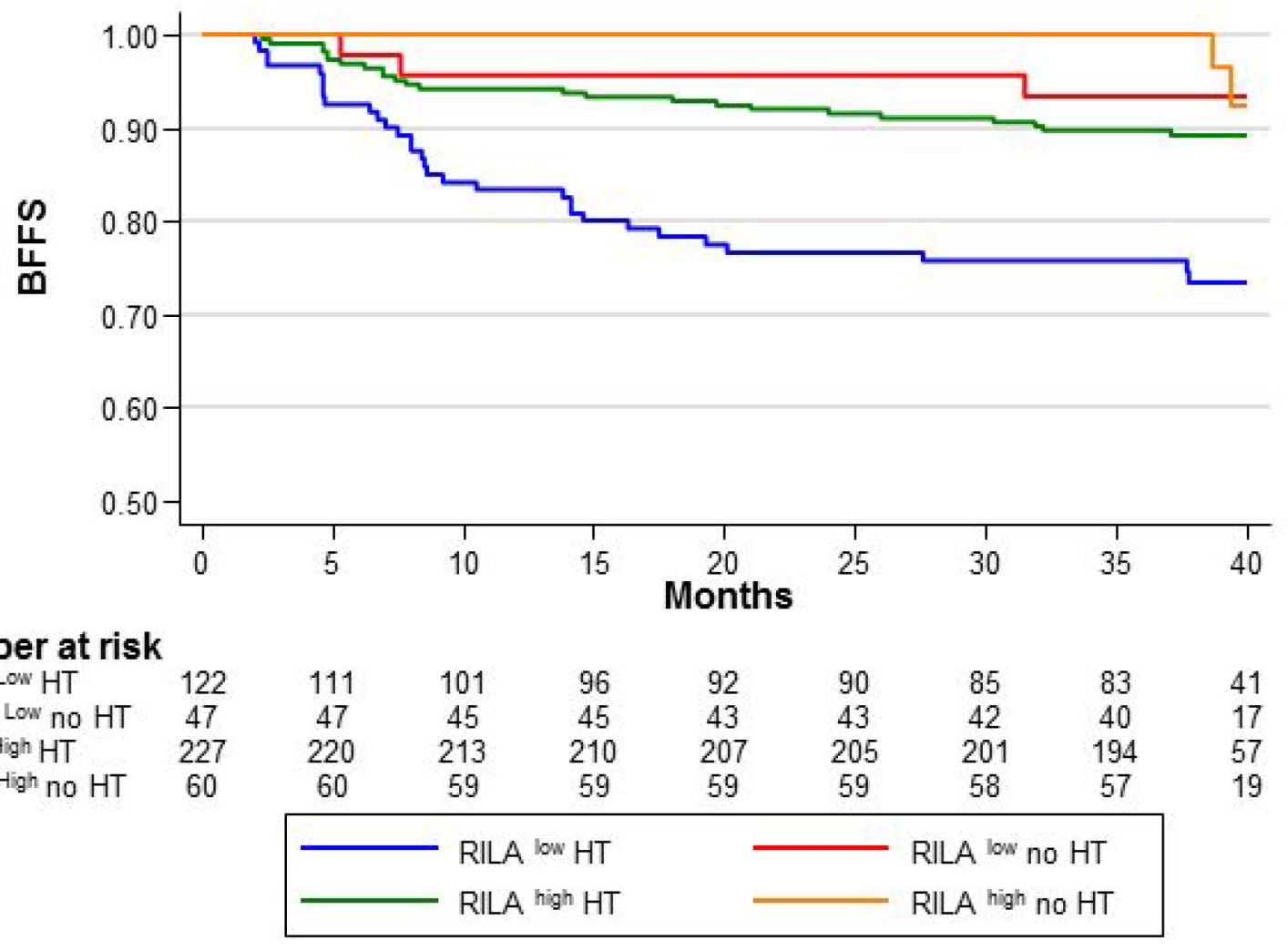

Figure 1: Breast fibrosis-free survival (BFFS) according to the RILA score $\left(<12 \%\right.$, RILA ${ }^{\text {LOW }}$ and $\geq 12 \%$, RILA $\left.{ }^{\mathrm{HIGH}}\right)$ and hormonotherapy (with HT, HT; or without, no HT). 


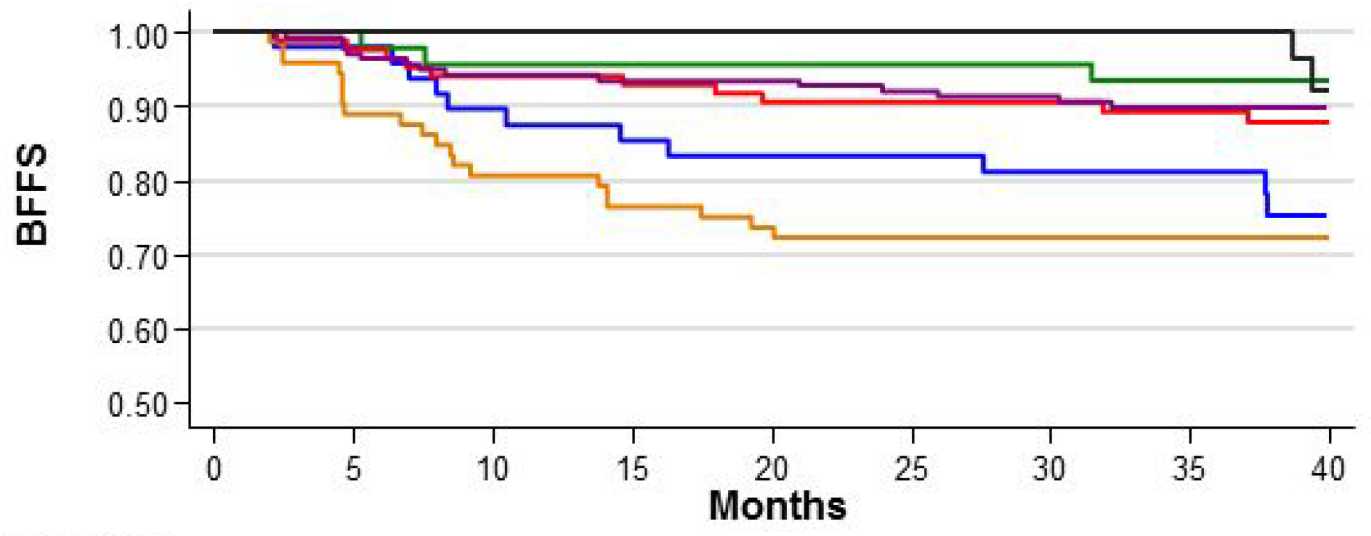

\begin{tabular}{|c|c|c|c|c|c|c|c|c|c|}
\hline \multicolumn{10}{|l|}{ Number at risk } \\
\hline RILA low; TAM & 49 & 47 & 43 & 41 & 40 & 40 & 37 & 37 & 17 \\
\hline RILA low; Al & 73 & 64 & 58 & 55 & 52 & 50 & 48 & 46 & 24 \\
\hline RILA low; no HT & 47 & 47 & 45 & 45 & 43 & 43 & 42 & 40 & 17 \\
\hline RILA high-TAM & 86 & 84 & 81 & 79 & 77 & 77 & 75 & 71 & 26 \\
\hline RILA high; $\mathrm{Al}$ & 141 & 136 & 132 & 131 & 130 & 128 & 126 & 123 & 31 \\
\hline RILA high; no HT & 60 & 60 & 59 & 59 & 59 & 59 & 58 & 57 & 19 \\
\hline
\end{tabular}

Figure 2: BFFS according to the RILA score (RILA ${ }^{\text {LOW }}$ or RILA $\left.{ }^{\mathrm{HIH}}\right)$ and the HT sub-categories: "TAM/no TAM", "AI/no AI", and "no HT".

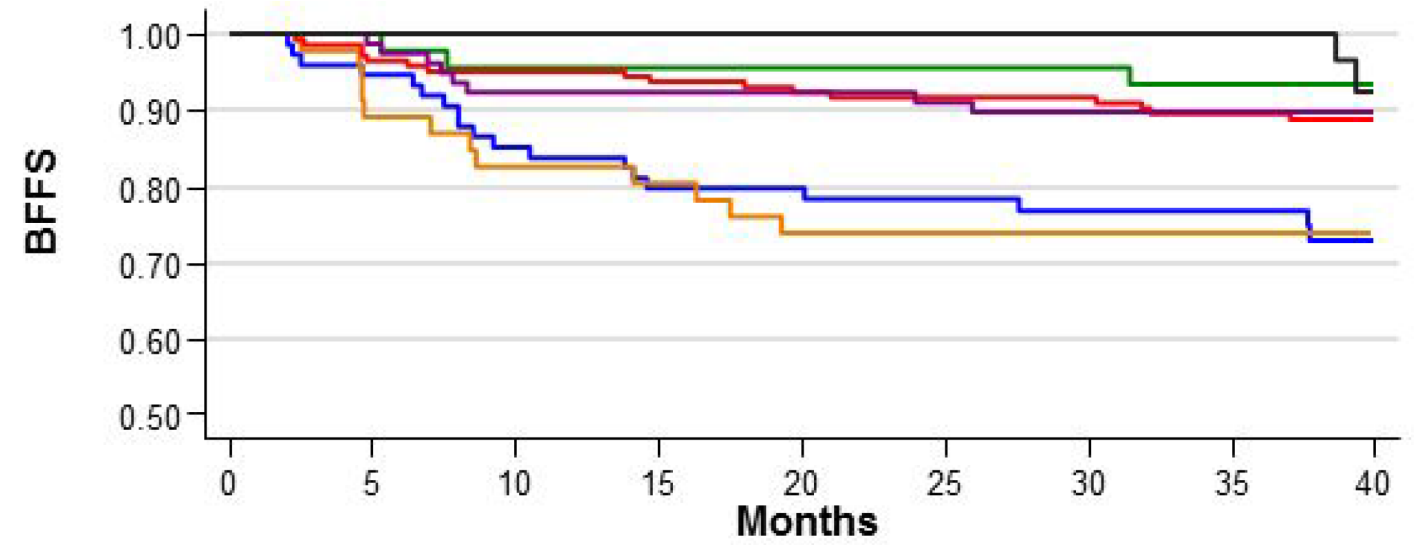

\begin{tabular}{|c|c|c|c|c|c|c|c|c|c|}
\hline \multicolumn{10}{|l|}{ Number at risk } \\
\hline RILA low- sq-HT & 75 & 70 & 63 & 59 & 58 & 56 & 51 & 49 & 20 \\
\hline RILA tow; $\mathrm{co}-\mathrm{HT}$ & 47 & 41 & 38 & 37 & 34 & 34 & 34 & 34 & 21 \\
\hline RILA bo: no HT & 47 & 47 & 45 & 45 & 43 & 43 & 42 & 40 & 17 \\
\hline RILA high; sq-HT & 148 & 142 & 140 & 137 & 134 & 133 & 131 & 124 & 34 \\
\hline RILA high; ${ }_{c 0}-\mathrm{HT}$ & 79 & 78 & 73 & 73 & 73 & 72 & 70 & 70 & 23 \\
\hline RILA high; no HT & 60 & 60 & 59 & 59 & 59 & 59 & 58 & 57 & 19 \\
\hline & & & &, so & & & 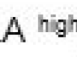 & & \\
\hline & & & & ow; $\mathrm{cc}$ & & & A high & HT & \\
\hline & & & $\mathrm{R}$ & ow; no & & & A high & & \\
\hline
\end{tabular}

Figure 3: BFFS according to the RILA score (RILA ${ }^{\text {LOW }}$ or RILA ${ }^{\mathrm{HIGH}}$ ) and HT timing relative to radiotherapy: concomitant "co-HT", sequential "sq-HT", or none "no HT". 
with radiotherapy increased radiation-induced pulmonary toxicity. However, they did not study the underlying mechanism of action. Other authors reported that the blood plasma level of TGF- $\beta$ - 1 was comparable between patients with breast cancer who developed or not lung fibrosis [28]. Moreover, they did not find any difference in lung fibrosis occurrence in patients who received TAM before or concomitantly with radiotherapy. Finally, Ryu and colleagues [29] showed that in a liver fibrosis rat model, TAM decreases both plasma and tissue TGF $\beta-1$ expression.

In conclusion, we showed that patients with low RILA scores are at higher risk of developing radiationinduced fibrosis [17]. Moreover, in these patients, HT further increased this risk, although preclinical data reported that TAM has an anti-fibrotic effect. Therefore, it is now important to study the molecular mechanisms to understand why HT significantly increases the risk of fibrosis only in patients identified as hypersensitive to radiotherapy.

On the basis of these results, a patent was filed for determining the risk of developing fibrosis in the clinical practice (patent No. PCT/EP2017/071887).

\section{MATERIALS AND METHODS}

\section{Study design, patients' selection and treatment}

This French prospective multicenter study (NCT00893035) enrolled 502 patients to assess RILA as a predictive tool of breast fibrosis after adjuvant breast radiotherapy [17]. Two treatment groups were characterized: patients who received adjuvant hormonotherapy $\left(\mathrm{HT}^{+}\right)$and patients who did not $\left(\mathrm{HT}^{-}\right)$. $\mathrm{HT}^{+}$patients were then divided in two subcategories (treated with TAM or AI) to study the effect of each pharmacological class on the risk of grade $\geq 2$ fibrosis. Moreover, hormonotherapy (HT) was defined as concomitant (co-HT) with radiotherapy when started before or the same day as radiotherapy, and sequential (sq-HT) when started after the last day of radiotherapy.

\section{Toxicity assessment}

Toxicities were prospectively evaluated at baseline, every week during radiotherapy, one, three and six months after radiotherapy completion and then every six months up to month 36. Cutaneous and subcutaneous toxicities were assessed using all the possible definitions described in the CTCAE v3.0 grading scale for the Dermatology/ Skin category. Grade $\geq 2$ breast fibrosis (primary endpoint) was blindly scored by at least two physicians.

\section{Radiation-induced lymphocyte apoptosis (RILA) [30]}

Briefly, $200 \mu \mathrm{l}$ of heparinized whole blood was cultured for 24 hours and then irradiated with 8 Gy or not (control samples). After 24 hours, CD8+ lymphocytes were separated from the other blood cells and their apoptosis percentage was assessed by flow cytometry. RILA was defined as the population of CD8+ lymphocytes with reduced DNA fluorescence and calculated as the percentage of total T-lymphocyte death induced by irradiation (8 Gy) minus the spontaneous cell death (0 Gy) [17].

\section{Statistical analyses}

Categorical variables were described as frequencies and percentages and continuous variables as medians and ranges. Comparisons between groups were performed with the Fisher's Exact and Kruskal-Wallis tests, respectively. Absolute changes in RILA scores before and after irradiation were evaluated as categorical variables. Three categories were constructed around the $33 \%$ quantile $(<12$, $12-20$, and $\geq 20$ ) and then merged in two categories, leading to two main subcategories: RILA low (RILA ${ }^{\text {low }}$ ) and RILA high $\left(\right.$ RILA $\left.^{\text {high }}\right)$ for values lower and higher than $12 \%$, respectively. Breast Fibrosis-Free Survival (BFFS) was defined as the interval between the radiotherapy start and the occurrence of a grade $\geq 2$ breast fibrosis. Patients alive who never experienced a grade $\geq 2$ breast fibrosis at the last follow-up were censored. BFFS rates were estimated using the Kaplan-Meier method. Ninety-five percent confidence intervals $(95 \% \mathrm{CI})$ were also determined.

The effect size was estimated by univariate analysis using the Cox proportional hazard regression model. Overall comparisons were performed using the log-rank test, and subgroup effect size comparisons with the Wald test. The median follow-up was estimated with the inverse Kaplan-Meier method. A $P$-value $<0.05$ was considered as significant. All statistical tests were two-sided. Analyses were carried out with the Stata software, v13.

\section{Abbreviations}

TAM: tamoxifen; AI: aromatase inhibitors; RILA: radiation-induced CD8+ T-lymphocyte apoptosis assay; $\mathrm{HT}^{+}$: patients group who was treated by adjuvant hormonotherapy; $\mathrm{HT}^{-}$: patients group who was not treated by adjuvant hormonotherapy; co-HT: concomitant hormonotherapy; sq-HT: sequential hormonotherapy; RILA $^{\text {low: }}$ RILA value lower than 12\%; RILA ${ }^{\text {high }}$ : RILA value higher than 12\%; BFFS: Breast Fibrosis-Free Survival; 95\% $\mathrm{CI}$ : ninety-five percent confidence intervals.

\section{Author contributions}

Authors who made substantial contributions to the conception and design, and/or acquisition of data, and/or analysis and interpretation of data; Authors who participated in the drafting of the article or in revising it critically for important intellectual conten: Celine Bourgier, Florence Castan, Sophie Gourgou, David Azria; 
Acquisition of data: Olivier Riou, Tan-Dat Nguyen, Karine Peignaux, Claire Lemanski, Jean-Léon Lagrange, Youlia Kirova, Eric Lartigau, Yazid Belkacemi, Sofia Rivera, Georges Noël, Sébastien Clippe, Françoise Mornex, Christophe Hennequin, Muriel Brengues, Pascal Fenoglietto, Esat Mahmut Ozsahin; Authors who gave their final approval of the version to be published: all authors.

\section{ACKNOWLEDGMENTS}

English editing by Elisabetta Andermarcher. This work was supported by an unrestricted educational grant from the French National Cancer Institute (PHRC INCa)

\section{CONFLICTS OF INTEREST}

Pascal Fenoglietto and David Azria participated in the development of NovaGray. All remaining authors declared that they have no conflict of interest.

\section{FUNDING}

Montpellier Cancer Institute (ICM Montpellier) received an unrestricted educational grant from the French National Cancer Institute (PHRC INCa) to cover the expenses for this trial. ICM Montpellier independently promoted the trial. The study funder had no role in the study design, data collection, data analysis, data interpretation, and report writing. The corresponding author had full access to all the data and the final responsibility for the decision to submit for publication.

\section{REFERENCES}

1. Darby S, McGale P, Correa C, Taylor C, Arriagada R, Clarke M, Cutter D, Davies C, Ewertz M, Godwin J, Gray R, Pierce L, Whelan T, et al. Effect of radiotherapy after breast-conserving surgery on 10-year recurrence and 15-year breast cancer death: meta-analysis of individual patient data for 10,801 women in 17 randomised trials. Lancet. 2011； 378:1707-16. https://doi.org/10.1016/ s0140-6736(11)61629-2.

2. Dowsett M, Forbes JF, Bradley R, Ingle J, Aihara T, Bliss J, Boccardo F, Coates A, Coombes RC, Cuzick J, Dubsky P, Gnant M, Kaufmann M, et al. Aromatase inhibitors versus tamoxifen in early breast cancer: patient-level meta-analysis of the randomised trials. Lancet. 2015; 386:1341-52. https://doi. org/10.1016/S0140-6736(15)61074-1S0140-6736(15)61074-1.

3. Al-Ghazal SK, Fallowfield L, Blamey RW. Does cosmetic outcome from treatment of primary breast cancer influence psychosocial morbidity? Eur J Surg Oncol. 1999; 25:571-3. https://doi.org/10.1053/ejso.1999.0708.
4. Darby SC, Ewertz M, Hall P. Ischemic heart disease after breast cancer radiotherapy. N Engl J Med. 2013; 368:2527. https://doi.org/10.1056/NEJMc1304601.

5. Azria D, Betz M, Bourgier C, Jeanneret Sozzi W, Ozsahin M. Identifying patients at risk for late radiation-induced toxicity. Crit Rev Oncol Hematol. 2012; 84:e35-41. https://doi. org/10.1016/j.critrevonc.2010.08.003.

6. Bourgier C, Lacombe J, Solassol J, Mange A, Pelegrin A, Ozsahin M, Azria D. Late side-effects after curative intent radiotherapy: Identification of hypersensitive patients for personalized strategy. Crit Rev Oncol Hematol. 2015; 93:312-9. https://doi.org/10.1016/j.critrevonc.2014.11.0 04S1040-8428(14)00188-7.

7. Schmidberger H, Hermann RM, Hess CF, Emons G. Interactions between radiation and endocrine therapy in breast cancer. Endocr Relat Cancer. 2003; 10:375-88.

8. Toillon RA, Magne N, Laios I, Lacroix M, Duvillier H, Lagneaux L, Devriendt D, Van Houtte P, Leclercq G. Interaction between estrogen receptor alpha, ionizing radiation and (anti-) estrogens in breast cancer cells. Breast Cancer Res Treat. 2005; 93:207-15. https://doi.org/10.1007/ s10549-005-5148-0.

9. Azria D, Larbouret C, Cunat S, Ozsahin M, Gourgou S, Martineau P, Evans DB, Romieu G, Pujol P, Pelegrin A. Letrozole sensitizes breast cancer cells to ionizing radiation. Breast Cancer Res. 2005; 7:R156-63.

10. Osborne CK, Boldt DH, Clark GM, Trent JM. Effects of tamoxifen on human breast cancer cell cycle kinetics: accumulation of cells in early G1 phase. Cancer Res. 1983; $43: 3583-5$.

11. Anscher MS, Murase T, Prescott DM, Marks LB, Reisenbichler H, Bentel GC, Spencer D, Sherouse G, Jirtle RL. Changes in plasma TGF beta levels during pulmonary radiotherapy as a predictor of the risk of developing radiation pneumonitis. Int J Radiat Oncol Biol Phys. 1994; 30:671-6.

12. Colletta AA, Wakefield LM, Howell FV, van Roozendaal KE, Danielpour D, Ebbs SR, Sporn MB, Baum M. Anti-oestrogens induce the secretion of active transforming growth factor beta from human fetal fibroblasts. Br J Cancer. 1990; 62:405-9.

13. Bentzen SM, Skoczylas JZ, Overgaard M, Overgaard J. Radiotherapy-related lung fibrosis enhanced by tamoxifen. J Natl Cancer Inst. 1996; 88:918-22.

14. Bese NS, Umay C, Yildirim S, Ilvan S, Dirican A, Salar S, Altug T, Ober A. The effects of tamoxifen on radiationinduced pulmonary fibrosis in Wistar albino rats: results of an experimental study. Breast. 2006; 15:456-60. https://doi. org/10.1016/j.breast.2005.04.016.

15. Kim D, Lee AS, Jung YJ, Yang KH, Lee S, Park SK, Kim W, Kang KP. Tamoxifen ameliorates renal tubulointerstitial fibrosis by modulation of estrogen receptor alpha-mediated transforming growth factor-beta1/Smad signaling pathway. Nephrol Dial Transplant. 2014; 29:2043-53. https://doi. org/10.1093/ndt/gfu240. 
16. Carthy JM, Sundqvist A, Heldin A, van Dam H, Kletsas D, Heldin CH, Moustakas A. Tamoxifen Inhibits TGF-betaMediated Activation of Myofibroblasts by Blocking NonSmad Signaling Through ERK1/2. J Cell Physiol. 2015; 230:3084-92. https://doi.org/10.1002/jcp.25049.

17. Azria D, Riou O, Castan F, Nguyen TD, Peignaux K, Lemanski C, Lagrange JL, Kirova Y, Lartigau E, Belkacemi Y, Bourgier C, Rivera S, Noel G, et al. Radiationinduced CD8 T-lymphocyte Apoptosis as a Predictor of Breast Fibrosis After Radiotherapy: Results of the Prospective Multicenter French Trial. EBioMedicine. 2015; 2:1965-73. https://doi.org/10.1016/j.ebiom.2015.10.024.

18. Azria D, Gourgou S, Sozzi WJ, Zouhair A, Mirimanoff RO, Kramar A, Lemanski C, Dubois JB, Romieu G, Pelegrin A, Ozsahin M. Concomitant use of tamoxifen with radiotherapy enhances subcutaneous breast fibrosis in hypersensitive patients. Br J Cancer. 2004; 91:1251-60.

19. Cecchini MJ, Yu E, Potvin K, D’Souza D, Lock M. Concurrent or Sequential Hormonal and Radiation Therapy in Breast Cancer: A Literature Review. Cureus. 2015; 7:e364. https://doi.org/10.7759/cureus.364.

20. Ahn PH, Vu HT, Lannin D, Obedian E, DiGiovanna MP, Burtness B, Haffty BG. Sequence of radiotherapy with tamoxifen in conservatively managed breast cancer does not affect local relapse rates. J Clin Oncol. 2005; 23:17-23.

21. Harris EE, Christensen VJ, Hwang WT, Fox K, Solin LJ. Impact of concurrent versus sequential tamoxifen with radiation therapy in early-stage breast cancer patients undergoing breast conservation treatment. J Clin Oncol. 2005; 23:11-6.

22. Pierce LJ, Hutchins LF, Green SR, Lew DL, Gralow JR, Livingston RB, Osborne CK, Albain KS. Sequencing of tamoxifen and radiotherapy after breast-conserving surgery in early-stage breast cancer. J Clin Oncol. 2005; 23:24-9.

23. Valakh V, Trombetta MG, Werts ED, Labban G, Khalid MK, Kaminsky A, Parda D. Influence of concurrent anastrozole on acute and late side effects of whole breast radiotherapy. Am J Clin Oncol. 2011; 34:245-8. https://doi.org/10.1097/ COC.0b013e3181df4b62.

24. Ishitobi M, Shiba M, Nakayama $T$, Motomura $K$, Koyama H, Nishiyama K, Tamaki Y. Treatment sequence of aromatase inhibitors and radiotherapy and long-term outcomes of breast cancer patients. Anticancer Res. 2014; $34: 4311-4$

25. Azria D, Belkacemi Y, Romieu G, Gourgou S, Gutowski M, Zaman K, Moscardo CL, Lemanski C, Coelho M, Rosenstein B, Fenoglietto P, Crompton NE, Ozsahin M. Concurrent or sequential adjuvant letrozole and radiotherapy after conservative surgery for early-stage breast cancer (CO-HO-RT): a phase 2 randomised trial. Lancet Oncol. 2010; 11:258-65. https:/doi.org/10.1016/ S1470-2045(10)70013-9.

26. Bourgier C, Kerns S, Gourgou S, Lemanski C, Gutowski M, Fenoglietto P, Romieu G, Crompton N, Lacombe J, Pelegrin A, Ozsahin M, Rosenstein B, Azria D. Concurrent or sequential letrozole with adjuvant breast radiotherapy: final results of the CO-HO-RT phase II randomized trialdagger. Ann Oncol. 2016; 27:474-80. https://doi. org/10.1093/annonc/mdv602.

27. Yavas G, Yavas C, Acar H, Toy H, Yuce D, Ata O. Comparison of the effects of aromatase inhibitors and tamoxifen on radiation-induced lung toxicity: results of an experimental study. Support Care Cancer. 2013; 21:811-7. https://doi.org/10.1007/s00520-012-1584-7.

28. Tell R, Edgren MR, Sverrisdottir A, Castro J, Fornander T, Hansson LO, Skog S, Lewensohn R. Radiation-induced cell cycle response in lymphocytes is not related to clinical side-effects in breast cancer patients. Anticancer Res. 2003; 23:3077-83.

29. Ryu SH, Chung YH, Lee JK, Kim JA, Shin JW, Jang MK, Park NH, Lee HC, Lee YS, Suh DJ. Antifibrogenic effects of tamoxifen in a rat model of periportal hepatic fibrosis. Liver Int. 2009; 29:308-14. https://doi. org/10.1111/j.1478-3231.2008.01811.x.

30. Ozsahin M, Crompton NE, Gourgou S, Kramar A, Li L, Shi Y, Sozzi WJ, Zouhair A, Mirimanoff RO, Azria D. CD4 and CD8 T-lymphocyte apoptosis can predict radiationinduced late toxicity: a prospective study in 399 patients. Clin Cancer Res. 2005; 11:7426-33. 